\title{
Prevalence and Predictors of Undiagnosed Hypertension in an Apparently Healthy Western Indian Population
}

\author{
Anand N. Shukla, ${ }^{1}$ Tarun Madan, ${ }^{1}$ Bhavesh M. Thakkar, \\ Meena M. Parmar, ${ }^{1}$ and Komal H. Shah ${ }^{2}$ \\ ${ }^{1}$ Cardiology Department, U. N. Mehta Institute of Cardiology and Research Centre (UNMICRC), Asarwa, Ahmedabad 380016, India \\ ${ }^{2}$ Research Department, U. N. Mehta Institute of Cardiology and Research Centre (UNMICRC), Asarwa, Ahmedabad 380016, India \\ Correspondence should be addressed to Anand N. Shukla; dranand1978@yahoo.co.in
}

Received 31 July 2014; Revised 19 January 2015; Accepted 16 February 2015

Academic Editor: Peter N. Lee

Copyright (C) 2015 Anand N. Shukla et al. This is an open access article distributed under the Creative Commons Attribution License, which permits unrestricted use, distribution, and reproduction in any medium, provided the original work is properly cited.

\begin{abstract}
This epidemiological study was designed to evaluate the prevalence of undetected hypertension in an apparently healthy western Indian population having no history of major illness. 3629 individuals of $\geq 18$ years of age were included in the study. Hypertension (HTN) was defined as systolic blood pressure (SBP) $\geq 140 \mathrm{mmHg}$ or diastolic blood pressure (DBP) $\geq 90 \mathrm{mmHg}$ and prehypertension (PHTN) as SBP $\geq 120-139 \mathrm{mmHg}$ or DBP $\geq 80-89 \mathrm{mmHg}$, but without HTN. The prevalence of undiagnosed HTN in the total population was $26 \%$ and was $11 \%$ and $40 \%$ in the young $(\leq 40$-year) and old ( $>40$-year) populations, respectively. The prevalence of PHTN, $40 \%$ in the overall population, was nearly the same in the young (39\%) and the old population (42\%). The risk factor most strongly associated with PHTN and HTN was obesity, showing the highest odds ratio in the overall (PHTN 2.14; 95\% CI 1.20-3.81; HTN 2.72; 95\% CI 1.53-4.85), the young (PHTN 2.29; 95\% CI 1.25-4.21; HTN 2.92; 95\% CI 1.59-5.35), and the old (PHTN 1.13; 95\% CI 0.65-1.96; HTN 1.38; 95\% CI 0.79-2.4) populations. Hypertension is a major risk factor for cardiovascular diseases which must not be ignored, especially in the western Indian population.
\end{abstract}

\section{Introduction}

Hypertension (HTN), being a major risk factor for cardiovascular diseases (CVDs), is an important issue of medical and public health. It is the most common condition seen in primary care which leads to myocardial infarction, stroke, renal failure, and death if not detected early and treated appropriately. The western Indian population is more susceptible to CVDs, being affected at a younger age ( $\leq 40$ years of age), with risk factors possibly also starting to show up at an early age period [1]. Prevalence of HTN increases with increasing age which could be used as a measure of its future CVD burden. More than half of the individuals of 60-69-year age group had HTN whereas in 70-year and older folks three quarters of the population are affected [2].

Some observational studies (a few with a study size of more than 1 million) indicate that death from ischemic heart disease (IHD) and stroke increases progressively and linearly from a blood pressure (BP) level as low as $115 \mathrm{mmHg}$ of systolic BP (SBP) and $75 \mathrm{mmHg}$ of diastolic BP (DBP). For every $20 \mathrm{mmHg}$ SBP or $10 \mathrm{mmHg}$ DBP increase, the rate of mortality doubles, mainly affecting individuals of the 40-89year age group $[3,4]$. Reports also suggest that the prevalence of HTN is rapidly increasing in developing countries and is one of the leading causes of death and disability [5]. Risk of cardiovascular events in Asian Indians is higher at relatively lower level of BP. In terms of attributable death, raised BP is one of the leading behavioral and physiological risk factors to which $13 \%$ of global deaths are attributed. Hypertension is reported to be the fourth contributor to premature death in developed countries and the seventh in developing countries [6].

Ethnic differences in HTN had been reported in various populations, including Indians [7] and hence the assessment of risk factors contributing to HTN in particular community is worth evaluating. The main aim of the present study was to investigate the prevalence and predictors of undiagnosed 
HTN in a western Indian population who is apparently healthy and disease free.

\section{Material and Methods}

This cross-sectional study, conducted at the U. N. Mehta Institute of Cardiology and Research center from SeptemberOctober 2013, was approved by the institutional ethics committee (UNMICRC/CARDIO/2014/57). Overall 4166 healthy individuals participated in the study.

2.1. Inclusion and Exclusion Criteria. Individuals of $\geq 18$ yrs of age and apparently with no history of any major illness were included in the study. Individuals with known HTN, diabetes, or ischemic heart disease or receiving drugs for these diseases currently or in the past, as well as pregnant women, were excluded from the study. Out of 4166 individuals, 3629 individuals were found to be eligible for the study. All patients had normal baseline electrocardiography (ECG) and 2D echocardiography. The details of demographic data, ethnicity, family history of HTN, sedentary life style, and smoking were collected for each individual with the help of prestandardized questionnaire. The family history of HTN was defined as any first-degree family member diagnosed with and/or receiving drug therapy for HTN.

2.2. Measurements. The accurate measurement of BP was a sine qua non for this study. The mercury equipment, properly prepared and positioned with the auscultatory method of BP measurement, was used. Participants were asked to rest for at least five minutes in a chair with feet on the floor and arm supported at the heart level. The standard cuff, large bladder for the fat arm and small bladder for the asthenic arm were used [2]. For measurement, the bladder was quickly inflated to $20 \mathrm{mmHg}$ higher than the point of disappearance of the radial pulse, and the bladder was deflated slowly at $2 \mathrm{mmHg}$ every second. JNC-VII criteria were used to diagnose HTN. The obesity was defined according to body mass index (BMI) (weight in kilogram/the square of height in meters) categories designed according to the WHO standards [8].

2.3. Blood Pressure Classification. Participants were divided into three categories on the basis of their BP as per JNC VII:

(1) normal BP (N): systolic $<120 \mathrm{mmHg}$ and diastolic $<80 \mathrm{mmHg}$;

(2) prehypertension (PHTN): either systolic BP 120 to $139 \mathrm{mmHg}$ or diastolic 80 to $89 \mathrm{mmHg}$, but not qualifying for HTN;

(3) hypertension (HTN): either systolic $\geq 140 \mathrm{mmHg}$ or diastolic $\geq 90 \mathrm{mmHg}$.

2.4. Risk Factor Definition. Positive family history was considered when a person had first-degree relatives (a parent, grandparent, or sibling) diagnosed with HTN. An individual performing physical activity for "less than 25-30 minutes per day" was considered to have a sedentary life style. Type A personality was assessed according to the Bortner classification scale [9], with current smoking status taken into account to categorize a person as smoker.
TABLE 1: Prevalence of prehypertension and hypertension in the total, young, and old populations.

\begin{tabular}{lccc}
\hline & $N(\%)$ & $\leq 40$ yrs. & $>40$ yrs. \\
\hline Normal (N) & $1204(33 \%)$ & $865(50 \%)$ & $339(18 \%)$ \\
Prehypertension (PHTN) & $1472(40 \%)$ & $684(39 \%)$ & $788(42 \%)$ \\
Hypertension (HTN) & $953(26 \%)$ & $186(11 \%)$ & $767(40 \%)$ \\
\hline Total & 3629 & 1735 & 1894 \\
\hline
\end{tabular}

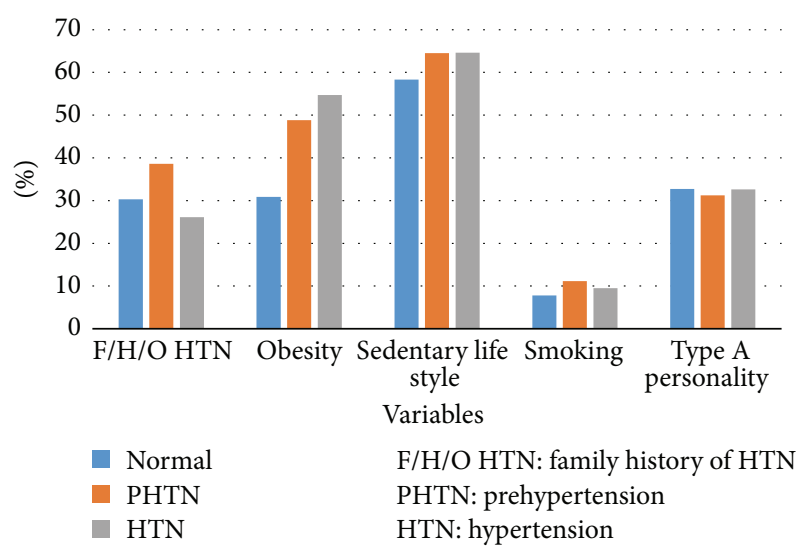

FIGURE 1: Frequency of risk factors associated with HTN in the normal, prehypertensive, and hypertensive populations.

2.5. Statistical Analysis. The statistical calculations were performed using SPSS software v 20.0 (Chicago, IL, USA). Quantitative data were expressed as mean $\pm \mathrm{SD}$ and qualitative data were expressed as a percentage. Univariate analysis of the continuous data was performed using Student's $t$-test, with the chi-square test used for the categorical data. The relationship of a particular risk factor to PHTN and HTN was assessed and expressed as odds ratio.

\section{Results}

Out of total 3629 eligible participants of the study, 1735 (48\%) were $\leq 40$ years of age. The overall prevalence of HTN and PHTN was $26 \%$ and $40 \%$, respectively. The prevalence of HTN was approximately $11 \%$ in the age group $\leq 40$ years whereas in the older population ( $>40$ years) it was found to be $40 \%$ (Table 1 ).

The risk factors associated with the PHTN and HTN were analyzed in the study population. The main factors associated with PHTN were sedentary life style (64.5\%), obesity (48.8\%), a positive family history for HTN (38.6\%), and smoking $(11.14 \%)$ whereas sedentary life style $(64.6 \%)$ and obesity $(54.7 \%)$ were the main associates of HTN (Figure 1). In the young population greater prevalence of sedentary life style (61.5\%), obesity (42.3\%), HTN family history $(31.3 \%)$, and smoking $(9.7 \%)$ was found in prehypertensive individuals. Similarly in hypertensive young population high frequency of sedentary life style (59.6\%), obesity (48.3\%), and family history (39.7\%) was found (Figure 2). The frequency of risk factors associated with PHTN and HTN in older individuals 


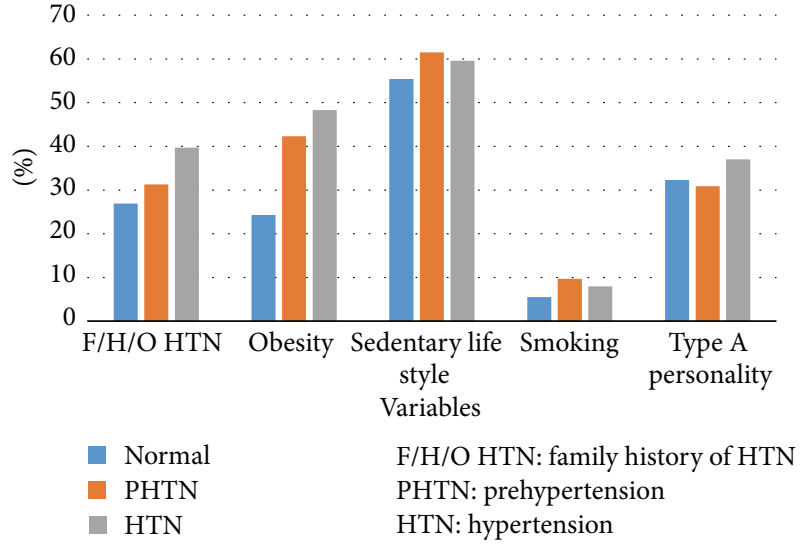

FIgURE 2: Frequency of risk factors associated with HTN in the normal, prehypertensive, and hypertensive populations for age $\leq 40$.

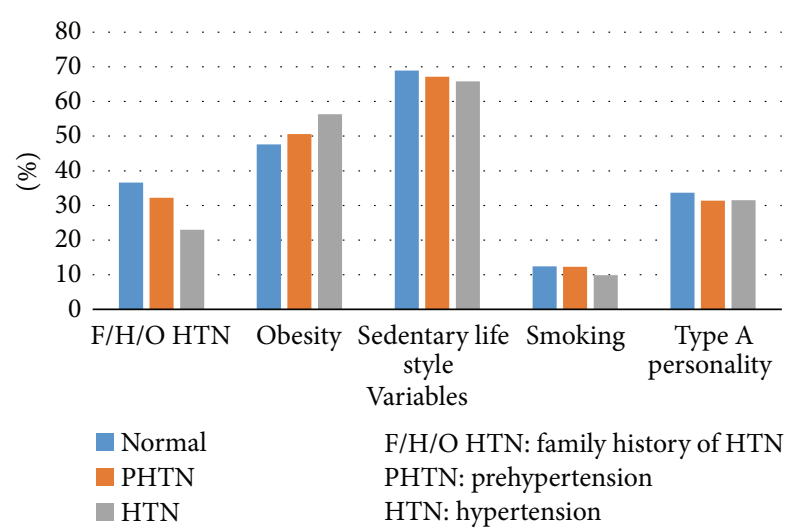

FIGURE 3: Frequency of risk factors associated with HTN in the normal, prehypertensive, and hypertensive populations for age $>40$.

is presented in Figure 3. Both sedentary life style $(67.1 \%$ and $65.8 \%$ ) and obesity ( $50.6 \%$ and $56.3 \%$ ) were considerably high in the older population with undiagnosed PHTN and HTN, respectively. The prevalence of HTN was also studied by $10-$ year age groups. It was approximately $10 \%$ in the $\leq 40$-year age group which increases up to three times (30\%) in the 41-50year age group and was more than $50 \%$ in the $61-70$-year age group (Figure 4).

As presented in Table 2 only obesity showed the significant positive association with PHTN (2.14; 95\% CI 1.20-3.81) and HTN $(2.72$; $95 \%$ CI $1.53-4.85)$ in the overall population. Similarly in the young obesity also showed the highest odds ratio for both PHTN $(2.29$; 95\% CI 1.25-4.21) and HTN (2.92; 95\% CI 1.59-5.35) (Table 3). In the older individuals the odds ratios (PHTN 1.13; 95\% CI 0.65-1.96; HTN 1.38; 95\% CI 0.792.4) were also highest for obesity, though less clearly elevated (Table 4).

\section{Discussion}

CVD is the largest cause of deaths in males $(20.3 \%)$ and females (16.9\%) and leads to 2 million deaths annually. The Atlas of heart disease and stroke has demonstrated a sustained

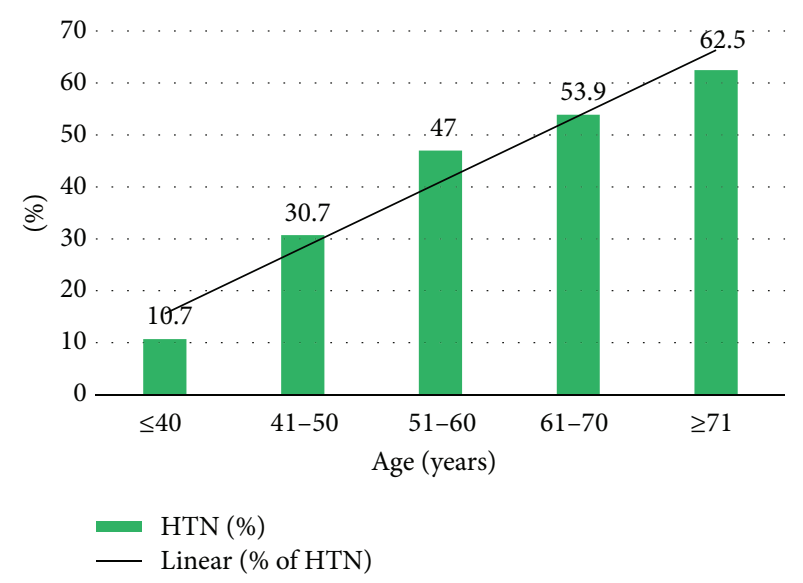

Figure 4: Prevalence of HTN by age.

TABLE 2: Odds ratio of factors associated with PHTN and HTN in overall population.

\begin{tabular}{lcccc}
\hline \multirow{2}{*}{ Variables } & \multicolumn{2}{c}{ PHTN } & \multicolumn{2}{c}{ HTN } \\
& Odds ratio & $95 \%$ CI & Odds ratio & $95 \%$ CI \\
\hline F/H/O HTN & 1.49 & $0.83-2.68$ & 0.82 & $0.44-1.52$ \\
Obesity & 2.14 & $1.20-3.81$ & 2.72 & $1.53-4.85$ \\
Sedentary life style & 1.35 & $0.76-2.38$ & 1.35 & $0.76-2.38$ \\
Smoking & 1.42 & $0.55-3.69$ & 1.28 & $0.48-3.38$ \\
Type A personality & 0.91 & $0.50-1.65$ & 1 & $0.55-1.80$ \\
\hline
\end{tabular}

$\mathrm{F} / \mathrm{H} / \mathrm{O} \mathrm{HTN}=$ family history of HTN, $\mathrm{CI}=$ confidence interval.

TABLE 3: Odds ratio of factors associated with PHTN and HTN in young population.

\begin{tabular}{lcccc}
\hline \multirow{2}{*}{ Variables } & \multicolumn{2}{c}{ PHTN } & \multicolumn{2}{c}{ HTN } \\
& Odds ratio & $95 \%$ CI & Odds ratio & $95 \%$ CI \\
\hline F/H/O HTN & 1.21 & $0.66-2.24$ & 1.8 & $0.99-3.27$ \\
Obesity & 2.29 & $1.25-4.21$ & 2.92 & $1.59-5.35$ \\
Sedentary life style & 1.34 & $0.76-2.35$ & 1.23 & $0.7-2.15$ \\
Smoking & 1.74 & $0.61-4.98$ & 1.36 & $0.45-4.1$ \\
Type A personality & 0.95 & $0.52-1.73$ & 1.25 & $0.69-2.24$ \\
\hline
\end{tabular}

$\mathrm{F} / \mathrm{H} / \mathrm{O} \mathrm{HTN}=$ family history of HTN, $\mathrm{CI}=$ confidence interval.

TABLE 4: Odds ratio of factors associated with PHTN and HTN in old population.

\begin{tabular}{lcccc}
\hline \multirow{2}{*}{ Variables } & \multicolumn{2}{c}{ PHTN } & \multicolumn{2}{c}{ HTN } \\
& Odds ratio & $95 \%$ CI & Odds ratio & $95 \%$ CI \\
\hline F/H/O HTN & 0.8 & $0.45-1.44$ & 0.51 & $0.27-0.94$ \\
Obesity & 1.13 & $0.65-1.96$ & 1.38 & $0.79-2.40$ \\
Sedentary life style & 0.91 & $0.50-1.65$ & 0.95 & $0.53-1.73$ \\
Smoking & 1 & $0.42-2.34$ & 0.82 & $0.33-1.98$ \\
Type A personality & 0.91 & $0.50-1.63$ & 0.95 & $0.53-1.73$ \\
\hline
\end{tabular}

$\mathrm{F} / \mathrm{H} / \mathrm{O} \mathrm{HTN}=$ family history of HTN, CI = confidence interval.

increase in mean BP level from a low $120 \mathrm{mmHg}$ to $130 \mathrm{mmHg}$ in 1997 as compared to 1942. Further modeled data project predicts that 107.3 million men and 106.2 million women will suffer from HTN by the year 2025 [10]. 
Hypertension was the leading attributable risk factor in the INTERSTROKE study for thrombotic or hemorrhagic strokes (34.6\%) while it is the fourth attributable risk factor for acute myocardial infarction as per INTERHEART study. The overall prevalence of HTN varies from low of $4.3 \%$ in 1963 to as high as approximately 50\% in some specific communities of Rajasthan and Kerala [11].

As HTN is a well-known modifiable risk factor for CVD, awareness regarding its early diagnosis and optimal management is "the need of the hour." Timely identification is often a crucial step and most important factor for the therapeutic management of HTN. Furthermore, classification of blood pressure values at progressive levels is used mainly to help in the clinical management of individual patients. A comprehensive strategy for reduction in complications, thus mortality and morbidity due to HTN, must include prevention strategies, increased awareness, early detection, adequate treatment, and strict control of blood pressure. This can be achieved only if the general public is aware of the risk factors, presenting features, and complications of HTN. Due to the multifactorial nature of HTN the management of risk factors contributing to its development also plays a vital role in the disease management.

To the best of our knowledge this is the first large study to evaluate the prevalence of undiagnosed HTN in apparently healthy Western Indian population. The main finding of our study is the $26 \%$ prevalence of undiagnosed HTN in apparently healthy Western Indian population. The incidence of HTN has increased in both urban and rural populations. Rajasthan exhibited the highest prevalence in the rural population, while prevalence in the urban population did not vary greatly in different regions. Metropolitan cities such as Mumbai had the highest prevalence of HTN, contrary to less populated cities, where prevalence of HTN was curtailed [1216]. Age group wise prevalence (10-year difference) indicates progressive increase from approximately $11 \%$ in $<40$ years of age to more than $50 \%$ at $60-69$-year age group [17-20]. The results from our study also show that the prevalence of HTN increases with age.

In our study a significant positive association between obesity and HTN was observed in the overall and young population as supported by several other reports also [21, 22]. Often this relationship which is "two-way street" in nature needs to be addressed early to prevent micro- and macrovascular complications. According to Framingham investigators an obese individual possesses higher risk of developing HTN as $10 \%$ rise in BMI is associated with $7 \mathrm{mmHg}$ rise in SBP [23]. The same study also revealed that tendency of gaining weight is significantly higher in hypertensive population as compared to their normotensive counterparts [24] and hence by developing awareness of exercise and prevention of obesity, the prevalence of HTN can be reduced.

\section{Conclusion}

From the study results we conclude that the prevalence of undetected HTN and PHTN is alarmingly high in an apparently healthy western Indian population. Major risk factor for the development of HTN was found to be obesity which is a modifiable risk factor and could be worked upon by following an active lifestyle and keeping an eye on BMI scores.

\section{Limitation of the Study}

(1) The majority of participants belonged to the urban class, so the HTN prevalence reflects this.

(2) Moreover, another limitation is moderate study size.

\section{Conflict of Interests}

The authors declare that there is no conflict of interests regarding the publication of this paper.

\section{Acknowledgments}

The authors would like to thank Dr. S. B. Dalal: respected mentor, Dr. R. K. Patel: Director of U. N. Mehta Institute of Cardiology and Research Center, Health and Family Welfare Department, Government of Gujarat, and Ms. Priyanka Patel: Research Assistant.

\section{References}

[1] K. H. Sharma, S. Sahoo, K. H. Shah, A. K. Patel, N. D. Jadhav, and M. M. Parmar, "Are Gujarati Asian Indians 'older' for their 'vascular age' as compared to their 'Chronological age'?" Quarterly Journal of Medicine, vol. 108, no. 2, pp. 105-112, 2014.

[2] P. A. James, S. Oparil, B. L. Carter et al., "2014 evidence-based guideline for the management of high blood pressure in adults: report from the panel members appointed to the Eighth Joint National Committee (JNC 8)," The Journal of the American Medical Association, vol. 311, no. 5, pp. 507-520, 2014.

[3] S. Lewington, R. Clarke, N. Qizilbash, R. Peto, and R. Collins, "Age-specific relevance of usual blood pressure to vascular mortality: a meta-analysis of individual data for one million adults in 61 prospective studies," The Lancet, vol. 360, no. 9349, pp. 1903-1913, 2002.

[4] A. V. Chobanian, G. L. Bakris, H. R. Black et al., "The seventh report of the joint national committee on prevention, detection, evaluation, and treatment of high blood pressure: the JNC 7 report," Journal of the American Medical Association, vol. 289, no. 19 , pp. 2560-2572, 2003.

[5] S. Mohan, N. Campbell, and A. Chockalingam, "Time to effectively address hypertension in India," Indian Journal of Medical Research, vol. 137, no. 4, pp. 627-631, 2013.

[6] "Indian guidelines on hypertension (I.G.H.) -III. 2013," Journal of the Association of Physicians of India, vol. 61, no. 2, supplement, pp. 6-36, 2013.

[7] N. C. Hazarika, D. Biswas, K. Narain, R. K. Phukan, H. C. Kalita, and J. Mahanta, "Differences in blood pressure level and hypertension in three ethnic groups of northeastern India," Asia-Pacific Journal of Public Health, vol. 12, no. 2, pp. 71-78, 2000.

[8] A. Rodgers and P. Vaughan, World Health Report 2002: Reducing Risks, Promoting Healthy Life, World Health Organization, Geneva, Switzerland, 2002.

[9] R. W. Bortner, "A short rating scale as a potential measure of pattern a behavior," Journal of Chronic Diseases, vol. 22, no. 2, pp. 87-91, 1969. 
[10] J. Mackay and G. A. Mensah, The Atlas of Heart Disease and Stroke, World Health Organization, 2004.

[11] P. C. Deedwania and R. Gupta, "HTN in South Asians," in HTN: A Companion Textbook to Braunwald's Heart Disease, H. R. Black and W. J. Elliott, Eds., WB Saunders, New York, NY, USA, 2nd edition, 2012.

[12] A. V. Chobanian, G. L. Bakris, H. R. Black et al., "The seventh report of the joint national committee on prevention, detection, evaluation, and treatment of high blood pressure: the JNC 7 report," Journal of the American Medical Association, vol. 289, no. 19, pp. 2560-2571, 2003.

[13] G. Mancia, G. de Backer, A. Dominiczak, R. Cifkova, R. Fagard, and G. Germano, "Guidelines for the management of arterial HTN The task force for the management of arterial HTN of the European Society of HTN (ESH) and of the European Society of Cardiology (ESC)," European Heart Journal, vol. 28, no. 12, pp. 1462-1536, 2007.

[14] R. Gupta, S. Guptha, K. K. Sharma, A. Gupta, and P. Deedwania, "Regional variations in cardiovascular risk factors in India: India heart watch," World Journal of Cardiology, vol. 4, no. 4, p. 112, 2012.

[15] B. Shah and P. Mathur, "Surveillance of cardiovascular disease risk factors in India: the need \& scope," Indian Journal of Medical Research, vol. 132, no. 5, pp. 634-642, 2010.

[16] K. Sliwa, S. Stewart, and B. J. Gersh, "Hypertension: a global perspective," Circulation, vol. 123, no. 24, pp. 2892-2896, 2011.

[17] J. M. Flack, "Epidemiology and unmet needs in HTN," Journal of Managed Care Pharmacy, vol. 13, no. 8, supplement, pp. 2-8, 2007.

[18] K. K. R. Reddy, A. P. Rao, and T. P. K. Reddy, "Socioeconomic status and the prevalence of coronary heart disease risk factors," Asia Pacific Journal of Clinical Nutrition, vol. 11, no. 2, pp. 98103, 2002.

[19] S. Yusuf, S. Hawken, S. Ounpuu et al., "Effect of potentially modifiable risk factors associated with myocardial infarction in 52 countries (the INTERHEART study): case-control study," The Lancet, vol. 364, no. 9438, pp. 937-952, 2004.

[20] M. J. O’Donnell, X. Denis, L. Liu et al., "Risk factors for ischaemic and intracerebral haemorrhagic stroke in 22 countries (the INTERSTROKE study): a case-control study," The Lancet, vol. 376, no. 9735, pp. 112-123, 2010.

[21] A. Humayun, A. S. Shah, and R. Sultana, "Relation of hypertension with body mass index and age in male and female population of Peshawar, Pakistan," Journal of Ayub Medical College, Abbottabad: JAMC, vol. 21, no. 3, pp. 63-65, 2009.

[22] R. Ahmad, TM. Khan, S. Zulfiqar, MA. Marwat, and I. Rehman, "Role of Body Mass Index (BMI) in the development of hypertension in adult population of District Swat. Biomedica," in Biomedica, vol. 23, pp. 23-41, 2007.

[23] S. Julius, M. Valentini, and P. Palatini, "Overweight and hypertension: a 2-way street?” Hypertension, vol. 35 , no. 3, pp. 807$813,2000$.

[24] R. J. Garrison, W. B. Kannel, J. Stokes III, and W. P. Castelli, "Incidence and precursors of hypertension in young adults: the Framingham Offspring Study," Preventive Medicine, vol. 16, no. 2, pp. 235-251, 1987. 


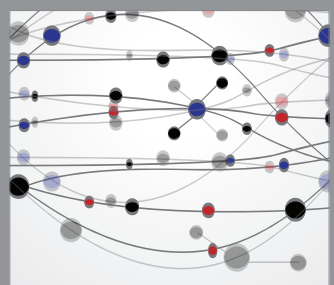

The Scientific World Journal
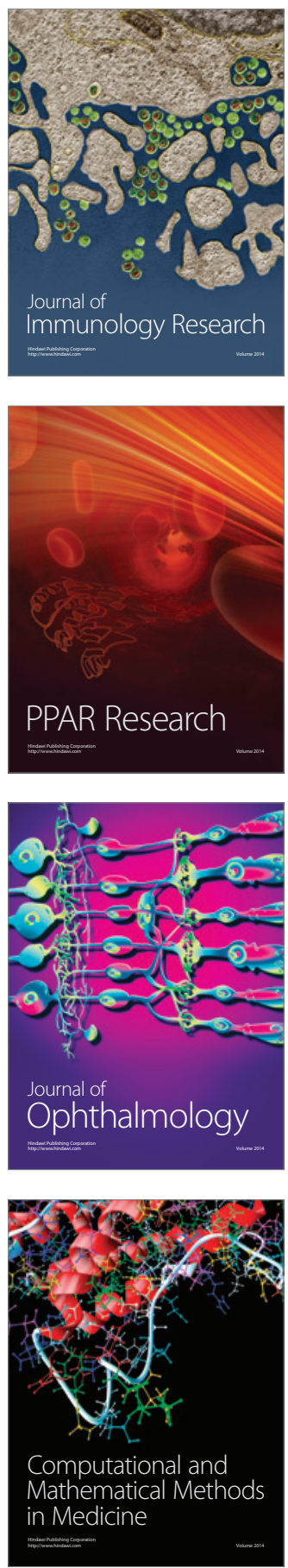

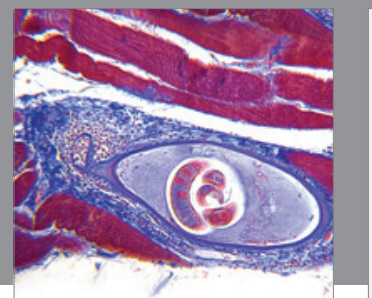

Gastroenterology

Research and Practice
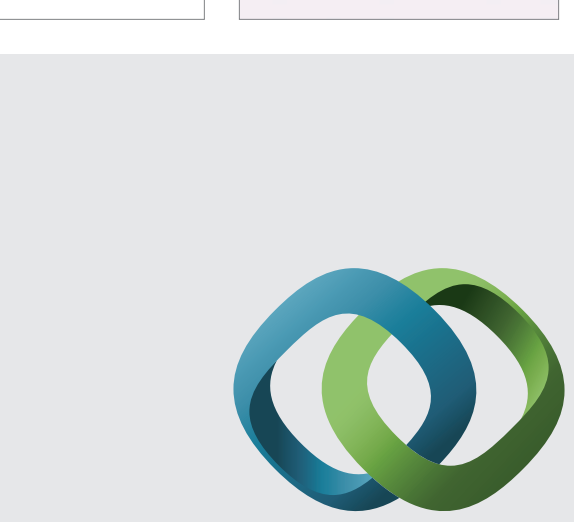

\section{Hindawi}

Submit your manuscripts at

http://www.hindawi.com
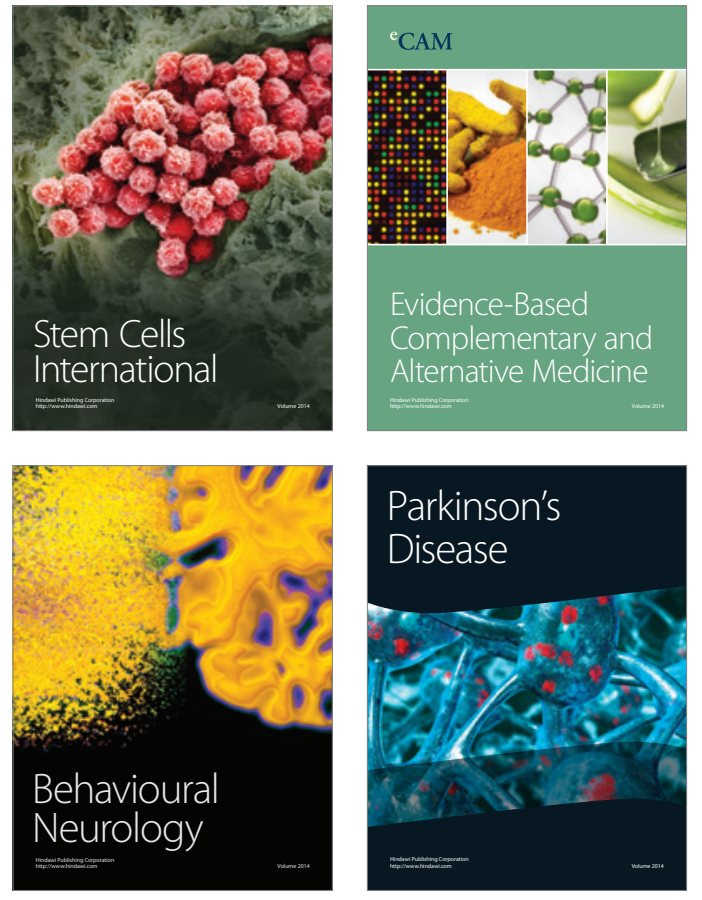
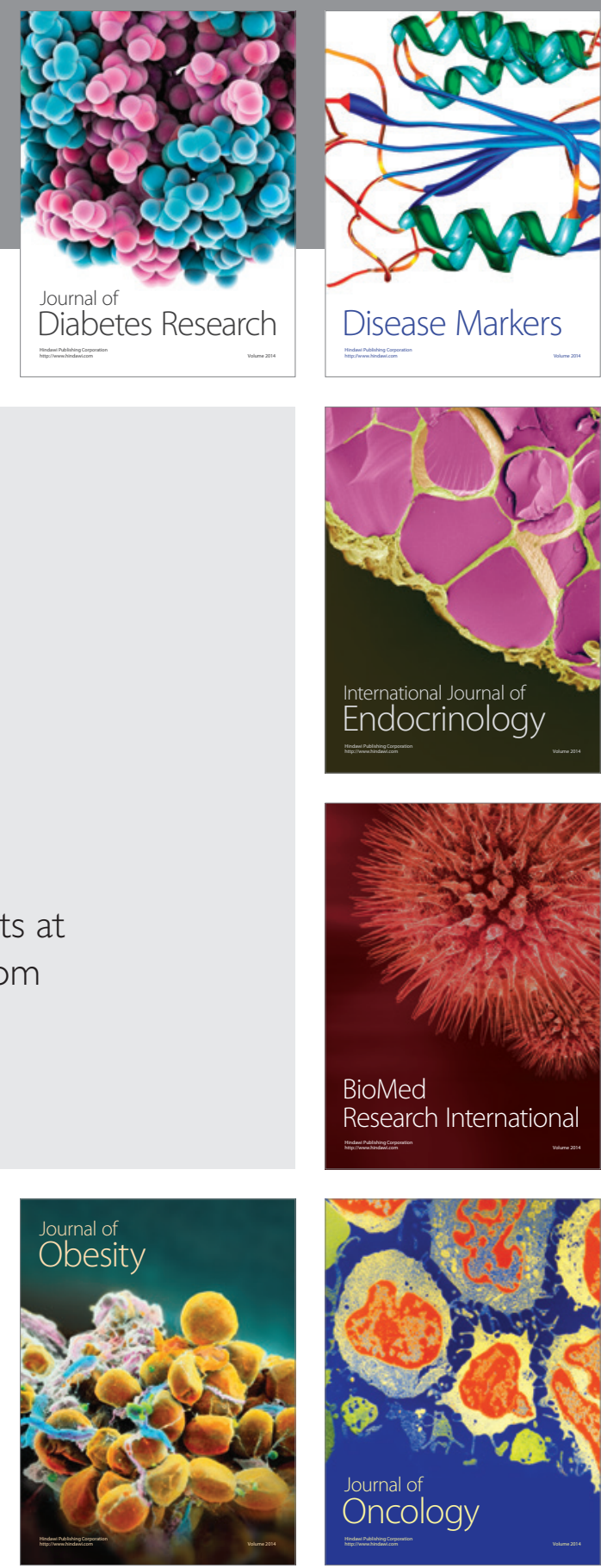

Disease Markers
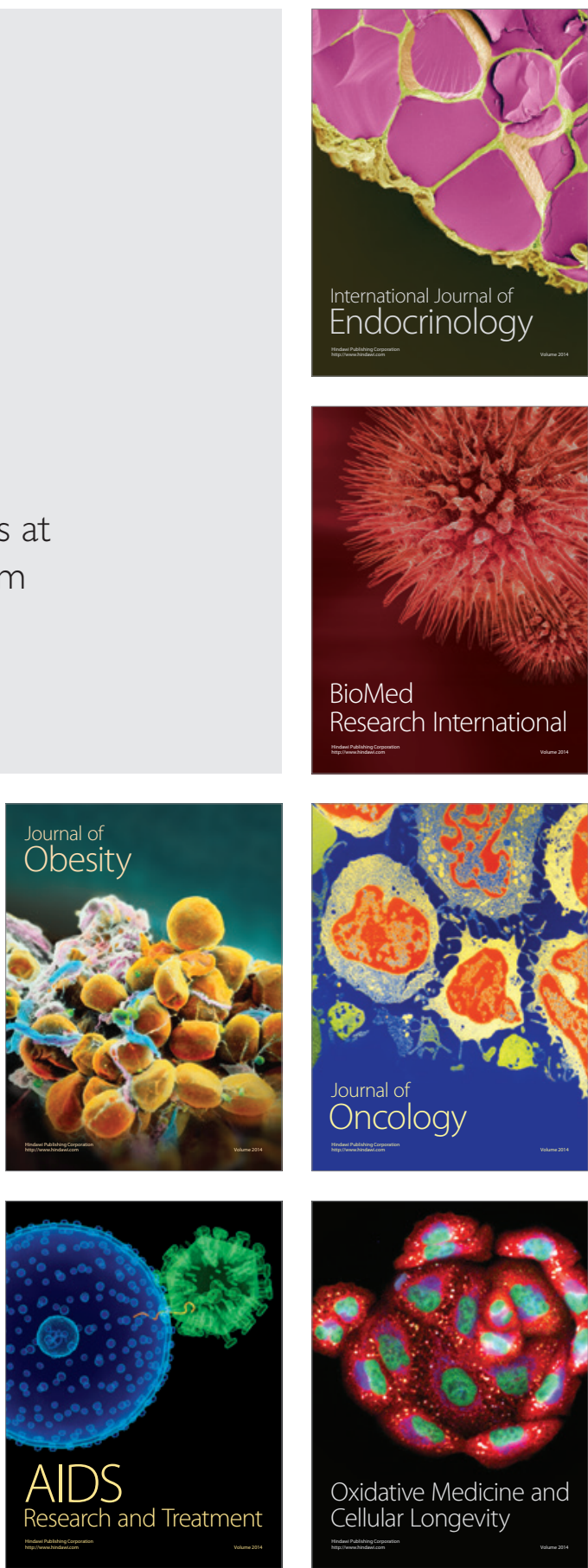